\title{
PENINGKATAN HASIL BELAJAR SISWA DENGAN PENERAPAN MODEL PEMBELAJARAN GROUP INVESTIGATION BERBASIS LINGKUNGAN SEKOLAH
}

\author{
Ni Wayan Ekayanti, Gusti Ayu Dewi Setiawati \\ Universitas Mahasaraswati Denpasar \\ email: nwekayanti@gmail.com
}

\begin{abstract}
ABSTRAK
Tujuan dari penelitian ini adalahmenganalisis peningkatan hasil belajar siswa dengan menggunakan lingkungan sekolah sebagai media pembelajaran dengan model group investigation. Metode yang digunakan dalam penelitian ini adalah eksperimen semu dengan menggunakan One Group Pretest-Posttest Design. Sampel penelitian adalah siswa kelas VIIB SMPN 5 Denpasar. Hasil penelitian menunjukkan bahwa ada perbedaan nyata hasil belajar $\left(p=0,000^{*}\right)$ antara sebelum dan setelah pembelajaran berbasis lingkungan sekolah dengan menggunakan model group investigation. Sehingga dapat disimpulkan bahwa model pembelajaran group investigation berbasis lingkungan sekolah sebagai media pembelajaran mampu meningkatkan hasil belajar siswa.
\end{abstract}

Kata Kunci: hasil belajar, peningkatan, group investigation

\section{ABSTRACT}

The purpose of this study is to analyze the improvement of student learning outcomes by using the school environment as a medium of learning with group investigation model. The method used in this research is quasi experiment using One Group Pretest-Posttest Design. The sample of this research is students of class VIIB SMPN 5 Denpasar. The results showed that there were significant differences in learning outcomes $(p=0,000 *)$ between before and after school-based learning by using group investigation model. So it can be concluded that the model of study group investigation based on school environment as a medium of learning can improve student learning outcomes.

Keywords: learning outcomes, improvement, group investigation

\section{PENDAHULUAN}

Tujuan pendidikan nasional menurut UU Pendidikan No 20 tahun 2003 adalah untuk mengembangkan potensi peserta didik agar menjadi manusia yang beriman dan bertakwa kepada Tuhan Yang Maha Esa, berakhlak mulia, sehat, berilmu, cakap, kreatif, mandiri, dan menjadi warga negara yang demokratis serta bertanggung jawab. Dari tujuan pendidikan itu, dapat dilihat bahwa pendidikan menginginkan SDM yang memiliki keseimbangan antara hard skills dan soft skill.

Banyak upaya yang telah dilakukan oleh pemerintah untuk meningkatkan pendidikan sains, pemerintah bahkan melakukan revisi kurikulum yang berlaku di Indonesia untuk mewujudkan tujuan pendidikan nasional. Hal tersebut terbukti dengan diberlakukannya kurikulum 2013 yang 
merupakan penyempurnaan KTSP yang menekankan pada empat Kompetensi Inti yang menggambarkan kualitas yang seimbang antara hard skills dan soft skills. Siahaan (2005) mengungkapkan ada lima unsur essensial yang ditekankan dalam model pembelajaran kooperatif yaitu: (1) Saling ketergantungan yang positif, (2) Interaksi berhadapan (face to face interaction), (3) Tanggung jawab individu, (4) Keterampilan sosial dan (5) Terjadi proses dalam kelompok (group processing). Siswa akan berkomunikasi, bekerjasama untuk mencapai tujuan kelompok yang telah ditetapkan. Untuk mencapai tujuan itu, individu dalam kelompok tersebut, harus terjadi group processing yang nantinya akan menyebabkan siswa saling bergantung positif satu sama lain, memiliki tanggung jawab individu untuk mensukseskan kelompok, mengasah kompetensi sosial siswa sehingga siswa tidak merasa canggung untuk berinteraksi dengan orang lain.

Salah satu model pembelajaran yang dapat digunakan untuk mengembangkan hard skills dansoft skills siswa adalah model pembelajaran kooperatif tipe Group Investigation berbasis lingkungan sekolah. Model pembelajaran kooperatif tipe GI didasari oleh gagasan John Dewey tentang pendidikan, dimana kelas merupakan cermin masyarakat dan berfungsi sebagai laboratorium untuk belajar tentang kehidupan di dunia nyata (Yasa, 2009). Dalam model pembelajaran kooperatif tipe GI, guru membagi kelas menjadi kelompok-kelompok kecil beranggota 4-6 orang yang heterogen dilihat dari jenis kelamin, etnik, kemampuan akademik dan juga dengan mempertimbangkan minat dan keakraban yang sama pada topik tertentu. Sintak dari model pembelajarankooperatif tipe GI terdiri dari 6 langkah, yaitu 1) pengelompokan siswa (grouping), 2) perencanaan tugas belajar (planning), 3) penyelidikan (investigation), 4) pengorganisasian atau penyiapan laporan (organizing), 5) mempresentasikan (presenting) dan 6) evaluasi (evaluating) (Rusman, 2013). Menurut Slavin (2007), model pembelajaran kooperatif tipe GI sangat ideal diterapkan dalam pembelajaran Biologi (IPA). Karena dengan topik IPA yang cukup luas dan desain tugas-tugas atau sub-sub topik yang mengarah ke medote ilmiah. Dan model pembelajaran ini mampu merangsang kompetensi sosial siswa seperti tenggang rasa sesama anggota kelompok, bekerjasama dan berbagi dengan anggota kelompok, memberikan kontribusi terhadap kelompok, berinteraksi dalam kelompok (Ekayanti, 2011). Tujuan dari penelitian ini adalah untuk menganalisis peningkatan hasil belajar siswa dengan menggunakan lingkungan sekolah sebagai media pembelajaran dengan model group investigation.

\section{METODE PENELITIAN}

Metode yang digunakan dalam penelitian ini adalah eksperimen semu dengan menggunakan One Group Pretest-Posttest Design. Populasi dalam penelitian ini adalah semua siswa kelas VII SMPN 5 Denpasar, dan sampel penelitian adalah siswa kelas VIIB. Penelitian ini dilaksanakan dari bulan Februari - Juli 2017. Data dianalisis menggunakan uji Wilcoxon signed rank test, dengan bantuan SPSS.

\section{HASIL DAN PEMBAHASAN}

Berdasarkan hasil penelitian didapatkan nilai pretes dan postes siswa, 
dimana rentang nilai terbesar diperoleh oleh nilai pretes dan posttest dapat dilihat pada siswa dengan kode R. lebih jelasnya, perbeaan Gambar 1 berikut ini.

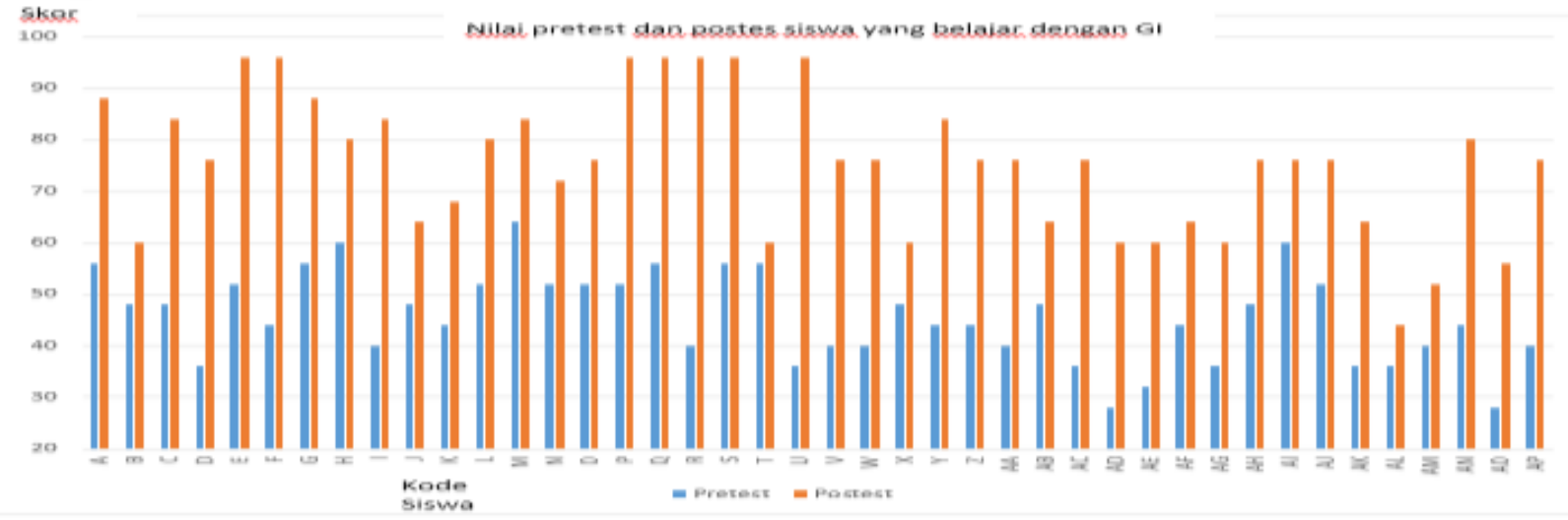

Gambar 1. Perbedaan nilai pretes dan postes siswa yang belajar dengan menggunakan GI

Data hasil belajar siswa dengan menggunakan model pembelajaran kooperatif tipe GI memiliki rentang gain skor $0,10-0,96 ; \mathrm{n}=42$, Gain skor minimum 0,10 ; Gain skor maksimum 0,96 ; rentangan $=0,86 ;$ banyak kelas $=15$; interval $=7$; rerata Gain skor $=0,67$ simpangan baku $=0,25 ;$ modus $=0,95$; median $=0,73$. Data hasil belajar siswa dengan menggunakan model pembelajaran kooperatif tipe GI dapat dilihat pada Tabel 1 berikut ini.

Tabel 1. Distribusi frekuensi gain skor hasil belajar IPA kelompok siswa yang belajar dengan model pembelajaran kooperatif tipe GI

\begin{tabular}{ccccccc}
\hline No & Interval & Batas Bawah & Batas Atas & $\begin{array}{c}\text { Titik } \\
\text { Tengah }\end{array}$ & Frekuensi & $\begin{array}{c}\text { Persentase } \\
(\%)\end{array}$ \\
\hline 1 & $0,10-0,16$ & 0,095 & 0,165 & 0,130 & 1 & 2,4 \\
2 & $0,17-0,23$ & 0,165 & 0,235 & 0,200 & 1 & 2,4 \\
3 & $0,24-0,29$ & 0,235 & 0,295 & 0,265 & 3 & 7,2 \\
4 & $0,30-0,35$ & 0,295 & 0,355 & 0,325 & 0 & 0,0 \\
5 & $0,36-0,41$ & 0,355 & 0,415 & 0,385 & 2 & 4,8 \\
6 & $0,42-0,47$ & 0,415 & 0,475 & 0,445 & 3 & 7,2 \\
7 & $0,48-0,53$ & 0,475 & 0,535 & 0,505 & 0 & 0,0 \\
8 & $0,54-0,59$ & 0,535 & 0,595 & 0,565 & 3 & 7,2 \\
9 & $0,60-0,65$ & 0,595 & 0,655 & 0,625 & 4 & 9,4 \\
10 & $0,66-0,71$ & 0,655 & 0,715 & 0,685 & 3 & 7,2 \\
11 & $0,72-0,77$ & 0,715 & 0,775 & 0,745 & 3 & 7,2 \\
12 & $0,78-0,83$ & 0,775 & 0,835 & 0,805 & 4 & 9,4 \\
13 & $0.84-0,89$ & 0,835 & 0,895 & 0,865 & 4 & 9,4 \\
14 & $0,90-0,95$ & 0,895 & 0,955 & 0,925 & 8 & 19,0 \\
15 & $0,96-1,02$ & 0,955 & 1,025 & 0,990 & 3 & 7,2 \\
Total & & & & & 42 & 100 \\
\hline
\end{tabular}

Agar sebaran data gain skor hasil belajar IPA kelompok siswa yang menggunakan model pembelajaran kooperatif tipe GI tampak lebih jelas, maka data disajikan dalam histogram dari 
frekuensi setiap kelas interval seperti Gambar 2 dibawah.

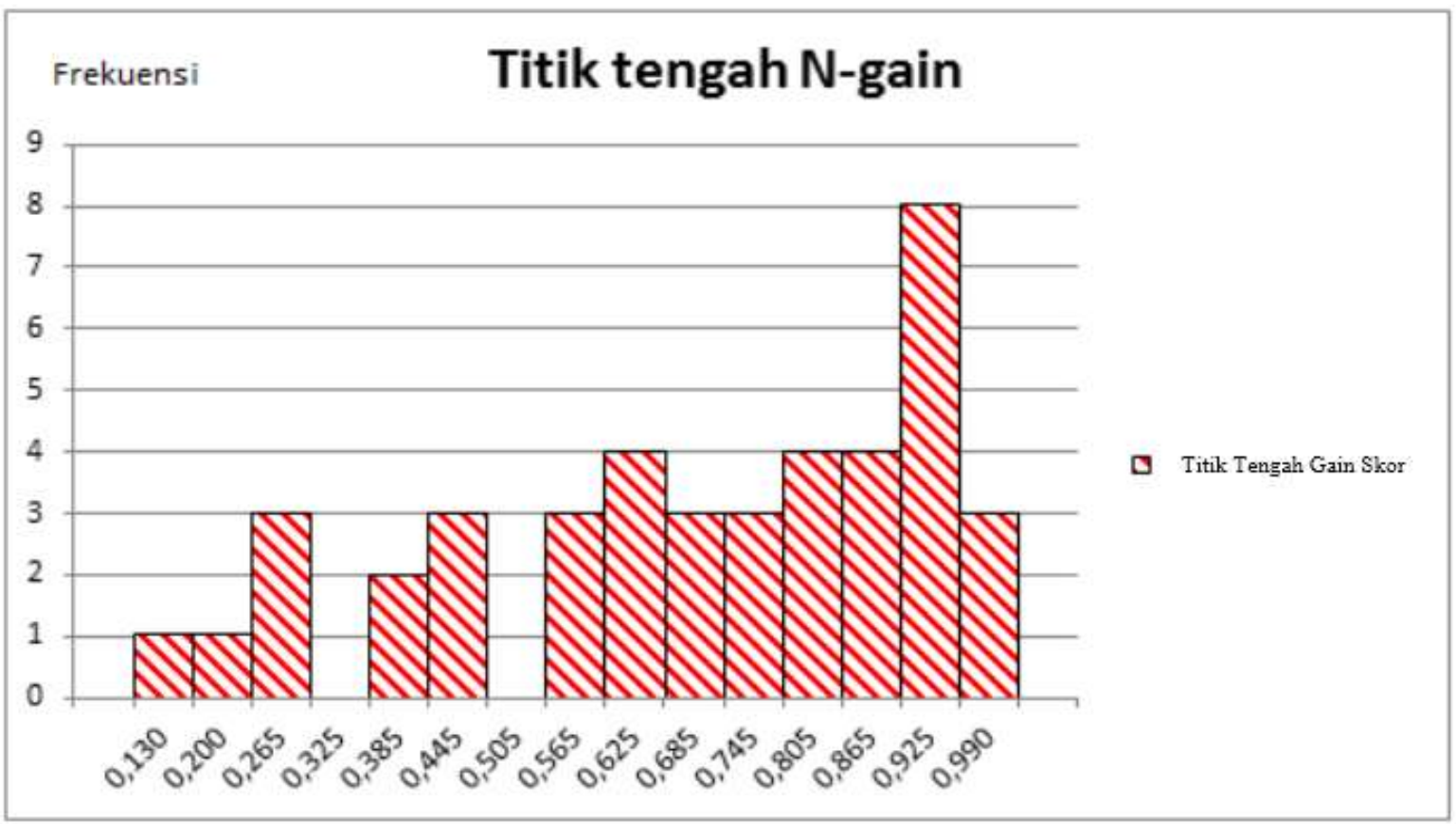

Titik Tengah Gain Skor A1

Gambar 2. Histogram frekuensi gain skor hasil belajar IPA kelompok siswa yang belajar dengan model pembelajaran kooperatif tipe GI

$-0,95$ yaitu sebanyak 8 orang (19\%).Untuk

Berdasarkan Gambar 1. terlihat bahwa frekuensi terbesar data gain skor hasil belajar IPA kelompok siswa yang menggunakan model pembelajaran kooperatif tipe GI terletak pada interval 0,90 menentukan peningkatan hasil belajar IPA kelompok siswa yang menggunakan model pembelajaran kooperatif tipe GI dapat dilihat pada Tabel 2. berikut ini.

Tabel 2. Klasifikasi gain skor hasil belajar IPA kelompok siswa yang belajar dengan model pembelajaran kooperatif tipe GI

\begin{tabular}{ccccc}
\hline No. & Rentang gain skor & Klasifikasi & Frekuensi & Persentase (\%) \\
\hline 1 & $\mathrm{~g}<0,3$ & $\mathrm{R}$ & 5 & 12 \\
2 & $0,3 \leq \mathrm{g} \leq 0,7$ & $\mathrm{Sd}$ & 15 & 35,2 \\
3 & $\mathrm{~g}>0,7$ & $\mathrm{~T}$ & 22 & 52,8 \\
\hline
\end{tabular}

Agar Tabel 2 dapat lebih mudah dimengerti, berikut ini disajikan diagram batang seperti Gambar 3. dibawah ini. 


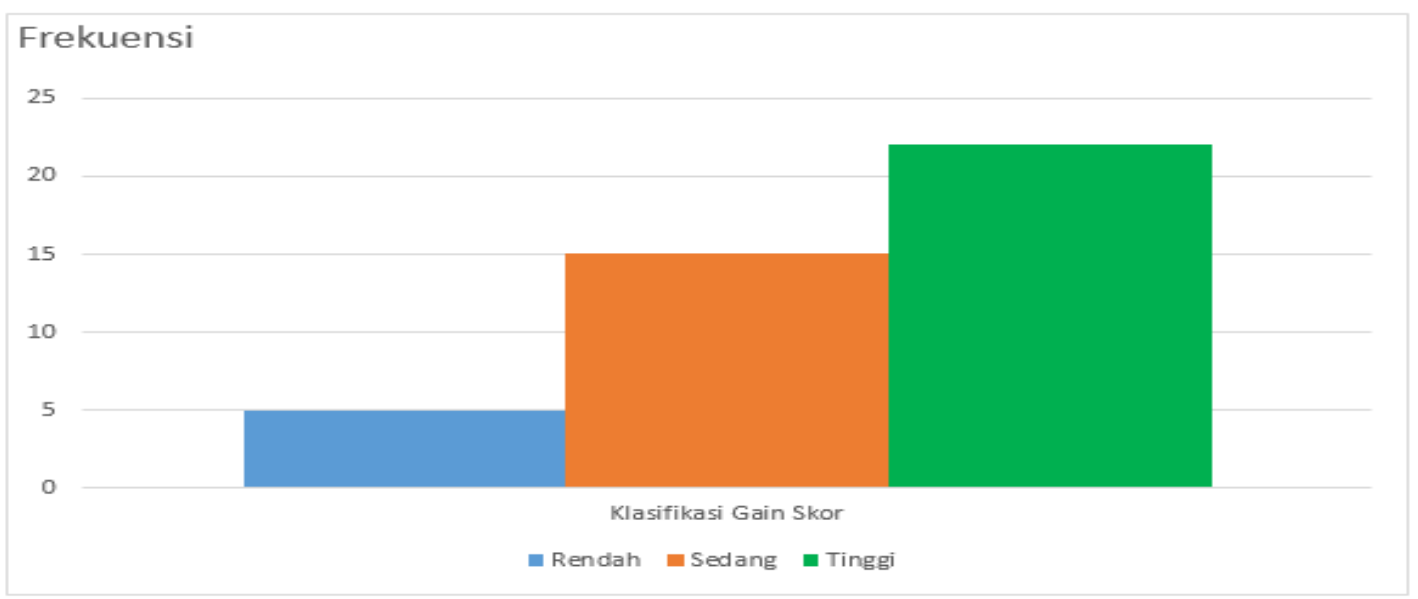

\section{Gambar 3. Histogram klasifikasi gain skor hasil belajar IPA kelompok siswa yang belajar dengan model pembelajaran kooperatif tipe GI}

Berdasarkan Gambar 3, terlihat bahwa 5 orang siswa (12\%) memiliki kualifikasi Gain skor rendah, 15 orang siswa $(35,2 \%)$ memiliki kualifikasi gain skor sedang dan 22 orang siswa $(52,8 \%)$ memiliki kualifikasi Gain skor tinggi. Hal ini menunjukkan bahwa Gain skor hasil belajar IPA kelompok siswa yang menggunakan model pembelajaran kooperatif tipe GI memiliki kecenderungan tinggi dengan frekuensi titik tengah tertinggi 0,93. Hal ini diperkuat oleh hasil uji statistik menggunakan uji Wilcoxon signed rank test yang menunjukkan hasil bahwa ada perbedaan nyata hasil belajar $(\mathrm{p}=0,000 *)$ antara sebelum dan setelah pembelajaran berbasis lingkungan sekolah dengan menggunakan model group investigation.

Hal ini sesuai dengan penelitian yang dilakukan oleh Rahmaniar (2014) yang menyatakan bahwa pembelajaran kooperatif tipe Group Investigation yang dipadukan dengan Problem Based Learning dapat meningkatkan motivasi belajar siswa dan hasil belajar siswa kelas XI IPA 6 SMA Negeri 7 Malang. Peningkatan hasil belajar dapat dilihat pada tahap melakukan penyelidikan sampai penyajian hasil akhir.Model pembelajaran kooperatif tipe GI merupakan model pembelajaran dengan menggunakan kelompok-kelompok kecil yang heterogen dari sisi kelamin, ras, agama, suku, kemampuan akademik (Rusman, 2013). Dengan adanya perbedaan-perbedaan itu diharapkan dapat memicu rasa ketergantungan positif diantara anggota kelompok-kelompok itu. Maksudnya dalam pembelajaran siswa tidak bisa bekerja secara individu, selalu diperlukan teman sebaya untuk menyelesaikan kegiatan pembelajaran. Dalam proses pembelajaran kooperatif, guru menciptakan suasana agar siswa saling membutuhkan. Hubungan saling membutuhkan inilah yang dimaksud dengan saling ketergantungan yang positif. Pembelajaran kooperatif tipe GI memberikan siswa kesempatan belajar untuk bekerjasama dengan teman dan belajar untuk lebih bertanggung jawab terhadap tugasnya karena dalam pembelajaran ini siswa mendapat tugas individu yang nantinya akan digabungkan untuk menghasilkan tugas kelompok. Ini berarti selain tanggung jawab kelompok, 
tanggung jawab individu juga sangat diperlukan dalam pembelajaran kooperatif. Artinya, selain tugas kelompok terselesaikan, tugas individu juga harus selesai.

Diharapkan dengan adanya kerjasama kelompok, telah terjadi transfer ilmu pengetahuan dari masing-masing individu ke individu yang lain. Yang pandai membantu temannya yang kurang pandai sehingga tugas kelompok dapat diselesaikan. Dalam kelompok belajar akan terjadi interaksiinteraksi yang disebutkan diatas, sehingga siswa akan saling membelajarkan dan pembelajaran oleh rekan sebaya (peerteaching) lebih efektif dari pada pembelajaran oleh guru. Hal inilah yang mendorong hasil belajar siswa akan lebih baik menggunakan model pembelajaran kooperatif tipe GI. Hal ini sesuai dengan penelitian yang dilakukan oleh Praptiningsih (2011) yang melibatkan persepsi 28 mahasiswa terhadap mata kuliah Ekoliterasi

\section{DAFTAR PUSTAKA}

Blatchford P, Peter K, Ed B, Maurice G. (2011). Toward a social pedagogy of classroom group work.Aviable: http://www.sciencedirect.com/science ?_ob=ArticleListURL\&_method=list \&_ArticleListID=669404698\&_st=17\&filterType $=\&$ sea rchtype $=$ a\&REC_ARTLIST_ID $=-$ 669405411\&originPage=rslt_list\&_ori gin=related_art\&_mlktType=Journal $\&$ md5=f39c6280fd234b07bf3611ccd04 dc1c3. Diakses tanggal 5 Juli 2017.

Depdiknas. (2008). Peran Pendidikan Sains. Tersedia:

http://www.kemendiknas.go.id/kemdik bud/. Diakses tanggal 23 Juni 2017.
Ketahanan Hayati, angket modal sosial dan survei modal sosial. Setelah di uji dengan ttest didapatkan hasil yang signifikan atau ada perbedaan nyata antara sebelum dan sesudah menggunakan metode pembelajaran tipe GI. Artinya pembelajaran kooperatif tipe GI sangat efektif digunakan dalam hal peningkatan akademik mahasiswa, kohesi sosial mahasiswa antar individu maupun kelompok. Pembelajaran kooperatif tipe GI adalah salah satu model pembelajaran yang mampu meningkatkan pemahaman mahasiswa terhadap mata kuliah EKH, peningkatan kohesi sosial kelompok dan kohesi sosial kelas.

\section{SIMPULAN}

Adapun simpulan dari penelitian ini adalah bahwa model pembelajaran group investigation (GI) dapat meningkatkan hasil belajar siswa $\quad\left(\mathrm{p}=0,000^{*}\right.$

Ekayanti, NW. (2011). Upaya Peningkatan Perilaku Anggota Dalam Kelompok dan Perilaku Berkelompok dalam Pembelajaran Ekoliterasi Berbasis Pembelajaran Kooperatif Tipe Kelompok Investigasi pada Mahasiswa Pendidikan Biologi Semester III Tahun Akademik 2008/2009. Jurnal Santiaji Pendidikan (JSP) Vol. 1 No 1, 11-17. ISSN 20879016. Unmas Denpasar

Nur, M. (2011). Model Pembelajaran Kooperatif. Surabaya: Pusat Sains dan Matematika Sekolah.

Praptiningsih, NWDS. (2011). Efektivitas Pembelajaran Kooperatif Group Investigation Terhadap Peningkatan Prestasi Akademik, Kohesi Sosial Kelas dan Kognesi Sosial Kelompok 
Bagi Mahasiswa Calon Guru. Jurnal Santiaji Pendidikan (JSP) Vol. 2 No 1, 11-17. ISSN 2087-9016. Unmas Denpasar

Rahmaniar, E. (2014). Penerapan Model Problem Based Learning dipadu Group Investigation untuk Meningkatkan Motivasi dan Hasil Belajar Siswa Kelas XI IPA 6 SMA Negeri 7 Malang. Skripsi: tidak diterbitkan. Tersedia: http://library.um.ac.id/ptk/index.php? mod=detail\&id=36822. $\quad$ Diakses: 7 Maret 2017.

Rusman. (2013). Model-model Pembelajaran. Jakarta: PT Raja Grafindo Persada

Siahaan. 2005. Pembelajaran Kooperatif. Jakarta: PT Raja Grafindo Persada

Slavin, ER. (2007). Cooverative Learning: Riset dan Praktik. Bandung: Nusa Media

Wilkinsona I. A.G \& Irene Y.Y. Fungb. (2013). Small-group composition and peer effects. Aviable: http://www.sciencedirect.com/science ?_ob=ArticleListURL\&_method=list \&_ArticleListID $=-$ 669404698\&_st $=17 \&$ filterType $=\&$ sea rchtype=a\&REC_ARTLIST_ID $=-$ 669405411\&originPage=rslt_list\&_ori gin=related_art\&_mlktType=Journal\& md5=f39c6280fd234b07bf3611ccd04 dc1c3. Diakses: 6 November 2014Diakses: 6 April 2017

Yasa, D. 2009. Pembelajaran Kooperatif Tipe Group Investigation (GI).http://annajahbisa.multiply.com/j ournal/item/7. Diakses 16 April 2017 